Article

\title{
Hydrophobicity Improvement of Cement-Based Materials Incorporated with Ionic Paraffin Emulsions (IPEs)
}

\author{
Jinyang Huo ${ }^{1,2}$, Zhenjun Wang ${ }^{2, *}$, Haoyan Guo ${ }^{2}$ and Yongfeng Wei ${ }^{1}$ \\ 1 Research and Development Center of Transport Industry of Technologies, Materials and Equipments of \\ Highway Construction and Maintenance. (Gansu Road \& Bridge Construction Group), \\ Lanzhou 730030, China; 2019031005@chd.edu.cn (J.H.); wei_yong_feng@sina.com (Y.W.) \\ 2 School of Materials Science and Engineering, Chang'an University, Xi'an 710061, China; hyguo@chd.edu.cn \\ * Correspondence: zjwang@chd.edu.cn
}

Received: 20 April 2020; Accepted: 13 July 2020; Published: 20 July 2020

check for updates

\begin{abstract}
Cement-based materials are non-uniform porous materials that are easily permeated by harmful substances, thereby deteriorating their structural durability. In this work, three ionic paraffin emulsions (IPEs) (i.e., anionic paraffin emulsion (APE), cationic paraffin emulsion (CPE), and non-ionic paraffin emulsion (NPE), respectively) were prepared. The effects of incorporation of IPEs into cement-based materials on hydrophobicity improvement were investigated by environmental scanning electron microscopy (ESEM), Fourier transform infrared (FTIR) spectroscopy, transmission and reflection polarizing microscope (TRPM) tests and correlation analyses, as well as by compressive strength, impermeability, and apparent contact angle tests. Finally, the optimal type and the recommended dose of IPEs were suggested. Results reveal that the impermeability pressure and apparent contact angle value of cement-based materials incorporated with IPEs are significantly higher than those of the control group. Thus, the hydrophobicity of cement-based materials is significantly improved. However, IPEs adversely affect the compressive strength of cement-based materials. The apparent contact angle mainly affects impermeability. These three IPEs impart hydrophobicity to cement-based materials. In addition, the optimal NPE dose can significantly improve the hydrophobicity of cement-based materials.
\end{abstract}

Keywords: ionic paraffin emulsions (IPEs); hydrophobicity improvement; impermeability; apparent contact angle; correlation analyses

\section{Introduction}

Cement-based materials are non-uniform porous materials that are easily permeated by harmful substances in water, thereby deteriorating their structural durability. Hydrophobicity is a key index to evaluate impermeability, corrosion resistance and durability of cement-based materials [1-6]. Hydrophobicity improvement of cement-based materials is effective to improve their corrosion resistance and durability via the decrease of their permeability, which deserves extensive attention [7-11].

The hydrophobicity of cement-based materials is predominantly improved by surface hydrophobic modification and internal hydrophobic modification [12-19]. Generally, surface hydrophobic modification involves the surface treatment of cement-based materials, such as coating, dipping and spraying. Previously, a hydrophobic release agent with $\mathrm{SiO}_{2}-\mathrm{CH}_{3}$ submicron-sized particles has been developed [12]; this agent increases the apparent contact angle of the cement mortar surface to higher than $145^{\circ}$, which can improve the hydrophobicity of cement mortar without reducing its compressive strength. Super-hydrophobic concrete has been developed by spraying ethylene-vinyl 
acetate copolymer to improve its structural property [16]. A silica-based hybrid nanocomposite, $\mathrm{SiO}_{2}$ /polymethylhydrosiloxane $\left(\mathrm{SiO}_{2} / \mathrm{PMHS}\right)$, has been used for the surface treatment of cement-based materials, which can reduce their water absorption and air permeability [17]. However, surface hydrophobic modification of cement-based materials exhibits limitations. Once the surface hydrophobic layer of cement-based materials is destroyed, the newly exposed part becomes hydrophilic, leading to the rapid decrease in their hydrophobicity.

On the other hand, internal hydrophobic modification involves the addition of hydrophobic substances during the mixing process of cement-based materials. As-prepared cement-based materials exhibit excellent hydrophobicity. Even if the surface of cement-based materials is destroyed, the newly exposed part still exhibits hydrophobicity. Common hydrophobic additives include silane, siloxane, stearic acid, penetron admix, and waste rubber powder [1,18,19]. A low-cost waterborne stearic acid emulsion has been introduced to improve the hydrophobicity and corrosion resistance of concrete [18]. However, the mechanical strength of concrete reportedly decreases. In addition, octyltriethoxysilane-based materials have been used for improving the hydrophobicity and durability of concrete [19]. However, the high cost of octyltriethoxysilane-based materials hinders their application. Therefore, it is imperative to prepare new cost-effective, suitable, and high-strength hydrophobic additives.

In this work, self-prepared ionic paraffin emulsions (IPEs) with excellent dispersion and high stability were used to improve the hydrophobicity of cement-based materials. The hydrophobicity of cement-based materials was improved by the combination of surface hydrophobic modification and internal hydrophobic modification. The compressive strength, impermeability, apparent contact angle, and microstructures of specimens were investigated and compared with those of the control group. The effect of IPEs on the hydrophobicity improvement of cement-based materials was analyzed. Meanwhile, correlation analyses among compressive strength, apparent contact angle, and impermeability were established. In addition, the optimal type and the recommended dose of IPEs were investigated to improve the hydrophobicity of cement-based materials. The objective of this work was examination of the hydrophobicity improvement of cement-based materials incorporated with IPEs. This work is of scientific interest for concrete compositions used in areas where corrosion acts with water as a support.

\section{Experimental}

\subsection{Materials}

Composite Portland cement, fine aggregate, fully refined paraffin, ionic emulsifiers (anionic, cationic, and non-ionic types), carboxymethylcellulose calcium, carrageenan, and mixing water (tap water, deionized water) were used in this work. Tap water was used to prepare the specimens, and deionized water was used to prepare self-prepared IPEs. Tables 1-3 show the properties of composite Portland cement, fine aggregate, and fully refined paraffin, respectively.

Table 1. Properties of composite Portland cement.

\begin{tabular}{|c|c|c|c|c|c|c|c|c|c|}
\hline \multirow[t]{2}{*}{ Density/(g/ $\left.\mathrm{cm}^{3}\right)$} & \multirow{2}{*}{ 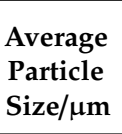 } & \multicolumn{2}{|c|}{ Setting Time/min } & \multicolumn{2}{|c|}{$\begin{array}{c}\text { Flexural } \\
\text { Strength/MPa }\end{array}$} & \multicolumn{2}{|c|}{$\begin{array}{l}\text { Compressive } \\
\text { Strength/MPa }\end{array}$} & \multicolumn{2}{|c|}{$\begin{array}{l}\text { Main Chemical } \\
\text { Composition/\% }\end{array}$} \\
\hline & & Initial & Final & $3 d$ & $28 d$ & $3 d$ & $28 \mathrm{~d}$ & $\mathrm{CaO}$ & $\mathrm{SiO}_{2}$ \\
\hline 3.150 & 20.786 & 141 & 233 & 3.8 & 6.2 & 18.9 & 35.8 & 60.1 & 20.8 \\
\hline
\end{tabular}

Table 2. Properties of fine aggregate.

\begin{tabular}{ccc}
\hline Density $/\left(\mathrm{g} / \mathrm{cm}^{3}\right)$ & Mud Content $/(\%)$ & Fineness Modulus \\
\hline 2.600 & 1.5 & 2.76 \\
\hline
\end{tabular}


Table 3. Properties of fully refined paraffin.

\begin{tabular}{cccccc}
\hline $\begin{array}{c}\text { Melting } \\
\text { Point } /\left({ }^{\circ} \mathbf{C}\right)\end{array}$ & $\begin{array}{c}\text { Containing } \\
\text { Oil } /(\mathbf{m} / \mathbf{m})\end{array}$ & $\begin{array}{c}\text { Penetration } \\
\text { Degree } /\left(\mathbf{2 5}{ }^{\circ} \mathbf{C},\right. \\
\mathbf{1 0 0 g}, \mathbf{1} / \mathbf{1 0 m m})\end{array}$ & Color Number & $\begin{array}{c}\text { Water-Soluble } \\
\text { Acid or Alkali }\end{array}$ & $\begin{array}{c}\text { Mechanical } \\
\text { Impurities and } \\
\text { Moisture }\end{array}$ \\
\hline $52-54$ & 0.55 & 15 & +30 & None & None \\
\hline
\end{tabular}

\subsection{Preparation of Self-Prepared Ionic Paraffin Emulsions (IPEs)}

Figure 1 shows the preparation of self-prepared IPEs. First, 36\% fully refined paraffin particles, 5\% ionic emulsifiers (anionic type: alkyl alcohol polyether sulfate; cationic type: cetylpyridinium bromide; non-ionic type: alkylphenol polyoxyethylene ether formaldehyde condensate), $0.5 \%$ carboxymethylcellulose calcium, $0.5 \%$ carrageenan, and $58 \%$ deionized water were placed in beakers; and then these beakers were placed in a bath with $60^{\circ} \mathrm{C}$ water. A beaker containing paraffin particles was removed from the water bath when paraffin particles were molten and the temperature was constant. Then, the deionized water heated to $60^{\circ} \mathrm{C}$ was poured into a colloid mill for preheating. Second, molten paraffin particles, ionic emulsifier, carboxymethylcellulose calcium, and carrageenan were gradually poured into the colloid mill. Third, the glass rod was used for one-way stirring to aid in the shearing and emulsification of the colloidal mill. Finally, emulsions were cooled to $20^{\circ} \mathrm{C}$, affording self-prepared IPEs.

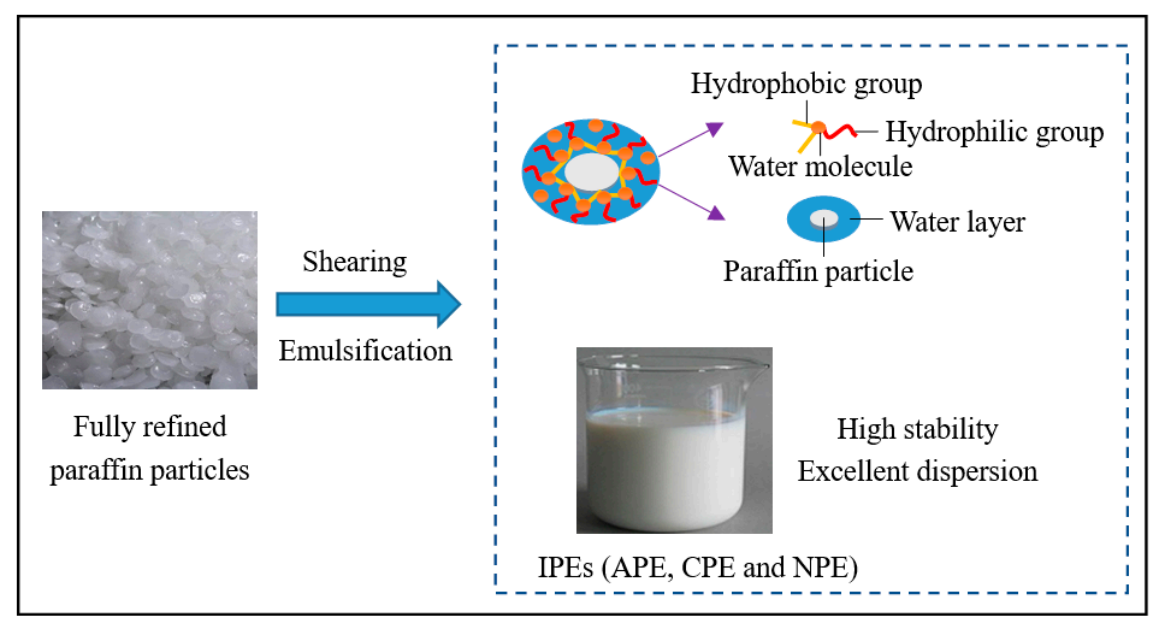

Figure 1. Preparation of self-prepared ionic paraffin emulsions (IPEs).

\subsection{Preparation of Specimens}

Two specimens were used in this work: cement paste and cement mortar specimens. Among these specimens, cement paste specimens were used for the compressive strength and environmental scanning electron microscopy (ESEM) tests, while cement mortar specimens were used for the impermeability test. Tables 4 and 5 show the mix proportions of cement paste specimens and cement mortar specimens, respectively.

Table 4. Mix proportion of cement paste specimens.

\begin{tabular}{cccc}
\hline IPE (\%) & Cement $(\mathbf{g})$ & Water $(\mathbf{g})$ & IPE $(\mathbf{g})$ \\
\hline 0.0 & 1350.0 & 472.5 & 0 \\
2.0 & 1350.0 & 456.3 & 27.0 \\
4.0 & 1350.0 & 440.1 & 54.0 \\
6.0 & 1350.0 & 423.9 & 81.0
\end{tabular}

Note: the dose of IPE is calculated according to the percentage of cement mass. 
Table 5. Mix proportion of cement mortar specimens.

\begin{tabular}{ccccc}
\hline IPE (\%) & Cement $(\mathbf{g})$ & Sand $(\mathbf{g})$ & Water $(\mathbf{g})$ & IPE $(\mathbf{g})$ \\
\hline 0.0 & 675.0 & 1012.5 & 236.3 & 0 \\
2.0 & 675.0 & 1012.5 & 228.2 & 13.5 \\
4.0 & 675.0 & 1012.5 & 220.1 & 27.0 \\
6.0 & 675.0 & 1012.5 & 212.0 & 40.5 \\
\hline
\end{tabular}

Note: the dose of IPE is calculated according to the percentage of cement mass.

First, for cement paste specimens, IPEs and water were mixed at a slow speed ( $140 \mathrm{r} / \mathrm{min})$ for $10 \mathrm{~s}$ using a mixer, followed by the slow addition of cement. The mixture was mixed at a slow speed $(140 \mathrm{r} / \mathrm{min})$ for $120 \mathrm{~s}$ and then at a high speed $(285 \mathrm{r} / \mathrm{min})$ for $120 \mathrm{~s}$. For cement mortar specimens, IPEs and water were mixed at a slow speed $(140 \mathrm{r} / \mathrm{min})$ for $10 \mathrm{~s}$ using a mixer, followed by the slow addition of cement. The mixture was mixed at a slow speed $(140 \mathrm{r} / \mathrm{min})$ for $60 \mathrm{~s}$, followed by the even addition of the fine aggregate (the feeding time of the fine aggregate was not longer than $30 \mathrm{~s}$ ). The mixture was mixed at a slow speed $(140 \mathrm{r} / \mathrm{min})$ for $120 \mathrm{~s}$ and then at a high speed $(285 \mathrm{r} / \mathrm{min})$ for $120 \mathrm{~s}$. Second, for cement paste specimens, the mixture was poured into molds (40 $\mathrm{mm} \times 40 \mathrm{~mm} \times 160 \mathrm{~mm}$ ) and cured at $20{ }^{\circ} \mathrm{C}$. For cement mortar specimens, the mixture was poured into frustum-shaped molds (top diameter of $70 \mathrm{~mm}$, bottom diameter of $80 \mathrm{~mm}$, and height of $30 \mathrm{~mm}$ ) and cured at $20^{\circ} \mathrm{C}$. After $24 \mathrm{~h}$, two specimens were demolded and placed into a standard curing room for 28 days. Third, surfaces of two specimens were polished using sandpaper and cleaned with a wet cloth after drying for $48 \mathrm{~h}$ in an oven at $60^{\circ} \mathrm{C}$. Then, IPEs were coated on surfaces of these two specimens by a coating machine. The thickness of the dry film coating as measured by a high-magnification digital microscope was about $350 \mu \mathrm{m}$. Finally, two specimens were dried indoors for 7 days.

\subsection{Test Methods}

\subsubsection{Fourier Transform Infrared (FTIR) Spectroscopy Test}

Compositions of IPEs were analyzed by Fourier transform infrared (FTIR) spectroscopy (Bruker; Karlsruhe, Germany). First, $5 \mathrm{~mL}$ of IPEs was placed in beakers. Then, beakers were placed in an oven at $50^{\circ} \mathrm{C}$ for $2 \mathrm{~h}$ to remove the water in IPEs. Second, beakers were removed until IPEs were cooled to $20^{\circ} \mathrm{C}$, followed by grinding IPEs into particles. Finally, IPE particles were placed on the sample table. FTIR diffuse reflection spectra were recorded from $4250 \mathrm{~cm}^{-1}$ to $750 \mathrm{~cm}^{-1}$ to examine the functional groups of the IPE particles.

\subsubsection{Compressive Strength Test}

The compressive strength of cement paste specimens was examined on an NYL-300D mechanical test machine (Wuxi Jianyi Instrument \& Machinery Co., Ltd; Wuxi, China). The specimens were compressed by the machine on an area of $40 \mathrm{~mm} \times 40 \mathrm{~mm}$ to obtain the compressive strength with a curing age of 28 days. The temperature and loading speed for the compressive strength test were $20^{\circ} \mathrm{C}$ and $500 \mathrm{~N} / \mathrm{s}$, respectively. Meanwhile, three specimens were prepared in each group. Finally, the error of data should not exceed $15.0 \%$ of the average value, and the average value was considered as the test result.

\subsubsection{Apparent Contact Angle Test}

The modified cement powder was composed of cement and 4.0\% IPEs. Then, it was dried for the apparent contact angle test. The dry modified cement powder was examined on a DACAT 21 dynamic contact angle measuring instrument. Figure 2 shows the test principle. The $C$ value (capillary coefficient) was determined by the measurement of n-hexane, and the apparent contact angle of the cement powder was calculated by the $C$ value (Figure 2). In addition, the instrument range for the apparent contact angle test was $0^{\circ}-90^{\circ}$. 


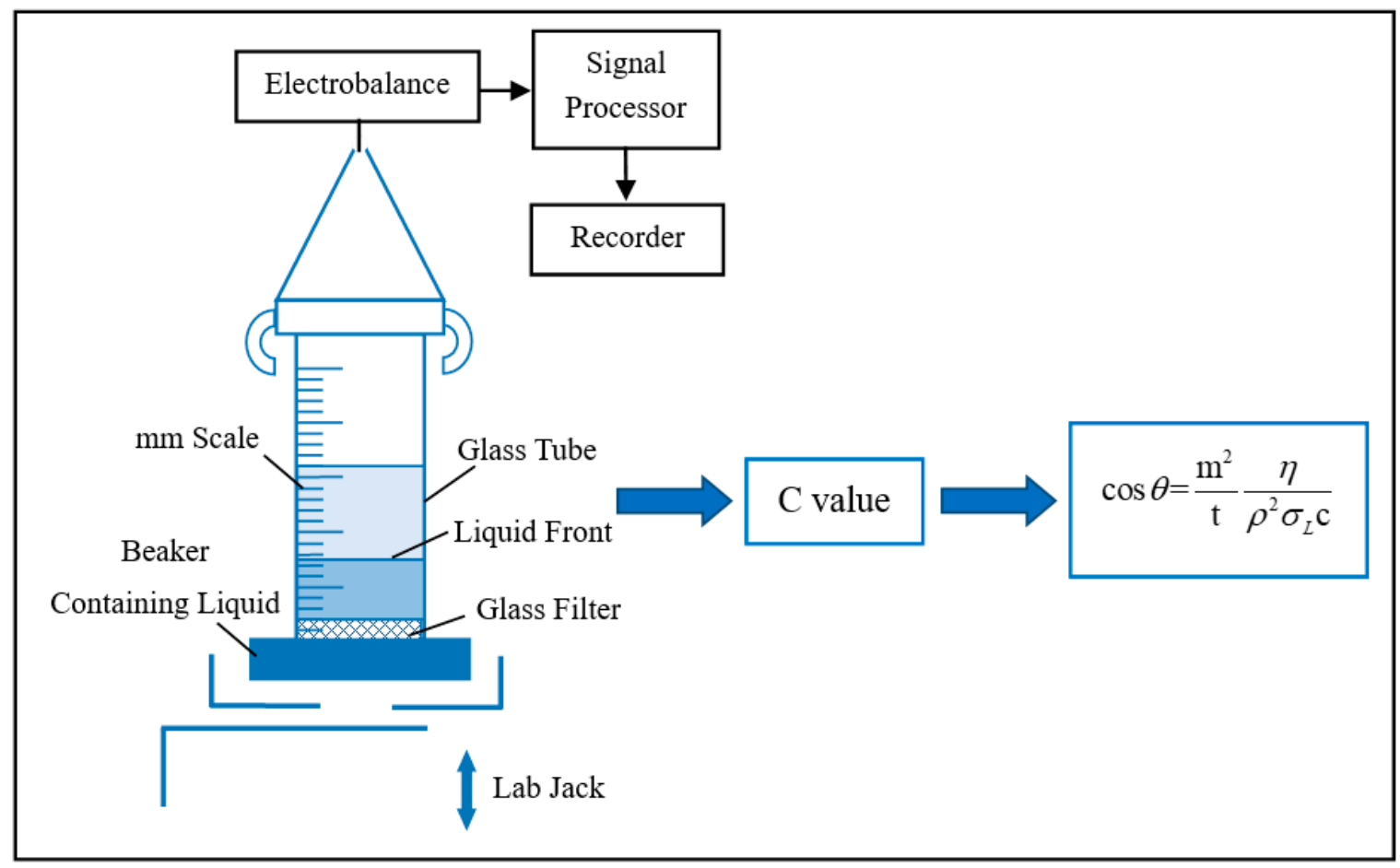

Figure 2. Washburn sorption method.

\subsubsection{Impermeability Test}

The impermeability of cement mortar with a curing age of $28 \mathrm{~d}$ was tested according to the Standard for Test Method of Basic Properties of Construction Mortar (JGJ/T 70-2009) [20]. First, the peripheries of six specimens in each group were sealed with sealing materials. Second, sealed specimens were placed into a cement mortar permeameter for the impermeability test. Then, the water pressure was started at $0.2 \mathrm{MPa}$ and then increased to $0.3 \mathrm{MPa}$ after maintaining a constant pressure for $2 \mathrm{~h}$. Then, the water pressure was increased by $0.1 \mathrm{MPa}$ every hour. The test could be stopped, and the water pressure at that time could be recorded when three of six specimens exhibited seepage on the end face. During the impermeability test, the test should be stopped, and the peripheries of specimens should be sealed again if the water seeped out from their peripheries. Then, the resealed specimens were placed again into the cement mortar permeameter to continue the impermeability test. The impermeability pressure value of specimens was calculated by the maximum pressure of four of six specimens in each group when seepage was not observed, as shown in Equation (1).

$$
P=H-0.1
$$

where, $P$ is the permeability pressure value of cement mortar, $\mathrm{MPa}$, and $H$ is the maximum water pressure among three of six specimens with permeation, MPa.

\subsubsection{Microstructure Tests}

In this work, two microstructure tests were conducted: transmission and reflection polarizing microscope (TRPM) test and environmental scanning electron microscopy (ESEM) test. For the TRPM test, IPEs were first spread uniformly on glass slides. Then, the glass slide was placed on an objective table for observation by TRPM at a temperature of $25^{\circ} \mathrm{C}$.

For the ESEM test, the effect of IPEs on the microstructure of the cement paste with a curing age of $28 \mathrm{~d}$ was investigated using an S-4800 cold-field ESEM. First, the specimen was cut into small particles, followed by their examination at an applied accelerating voltage of $5.0 \mathrm{kV}$ and a temperature of $25^{\circ} \mathrm{C}$. 


\section{Correlation Analyses}

\subsection{Non-Linear Correlation Analysis and Linear Correlation Analysis}

Non-linear correlation and linear correlation are common data analysis methods. In several practical problems, the relationship between variables is non-linear. Generally, there is some curve relationship between variables. For this relationship, a non-linear correlation analysis method for analyzing variables is utilized. Generally, a nonlinear regression model is expressed in Equation (2).

$$
Y=\varphi\left(x_{1}, x_{2}, \ldots, x_{m}, \beta_{1}, \beta_{2}, \ldots, \beta_{r}\right)+\varepsilon
$$

For a given set of observations $\left(x_{i}, y_{i}\right), i=1,2, \ldots, n$, Equation (2) can be revised as Equation (3).

$$
y_{i}=f\left(x_{i}, \theta\right)+\varepsilon_{i}, i=1,2, \ldots, n
$$

where, $y_{i}$ is a dependent variable; non-random variable $x_{i}=\left(x_{i 1}, x_{i 2}, \ldots, x_{i k}\right)^{\prime}$ is an independent variable; $\theta=\left(\theta_{0}, \theta_{1}, \ldots, \theta_{p}\right)^{\prime}$ is an unknown parameter vector; and $\varepsilon_{i}$ is a random error term, which satisfies the independently identical distribution; that is, Equation (4).

$$
\left\{\begin{array}{l}
E\left(\varepsilon_{i}\right)=0, i=1,2, \ldots, n \\
\operatorname{cov}\left(\varepsilon_{i}, \varepsilon_{j}\right)=\left\{\begin{array}{c}
\sigma^{2}, i=j \\
0, i \neq j
\end{array}(i, j=1,2, \ldots, n)\right.
\end{array}\right.
$$

Then, Equations (5) and (6) were used to solve nonlinear least-squares estimation (minimum $\theta$ ) of $\theta$.

$$
\begin{gathered}
Q(\theta)=\sum_{i=1}^{n}\left(y_{i}-f\left(x_{i}, \theta\right)\right)^{2} \\
\left.\frac{\partial Q}{\partial \theta_{j}}\right|_{q_{j}=\hat{q}_{j}} ^{j}=-\left.2 \sum_{i=1}^{n}\left(y_{i}-f\left(x_{i}, \hat{\theta}\right)\right) \frac{\partial f}{\partial \theta_{j}}\right|_{\theta_{j}=\hat{\theta}_{j}}=0,(j=0,1,2, \ldots, p)
\end{gathered}
$$

where, the regular expressions (Equation (6)) can be established by the differential method to solve $Q(\theta)$ (to obtain minimum $\hat{\theta}$ ), when the $f$ function is assumed to be continuous differentiable for $\theta$. Let the partial derivative of the $Q$ function to $\theta_{j}$ be 0 (Equation (6)). Equation (6) is generally solved by the Newton iterative method. In addition, $\hat{\theta}$ can be calculated by minimizing the residual sum of squares.

In this work, Origin 8.5 software was utilized to establish the non-linear fitting and linear fitting. The correlation coefficient $R^{2}$ was used for non-linear correlation analysis and linear correlation analysis. $R^{2}$ is a dimensionless quantity with a value between -1 and 1 . When $R^{2}<0$, the correlation between variables is negative. When $R^{2}>0$, the correlation between variables is positive. In addition, $\left|R^{2}\right|$ indicates the degree of correlation between variables. Generally, when $0.8<\left|R^{2}\right|<1.0$, the correlation between the two variables is extremely strong. When $0.6<\left|R^{2}\right|<0.8$, the correlation between the two variables is strong. When $0.4<\left|R^{2}\right|<0.6$, the correlation between the two variables is moderate. When $0.2<\left|R^{2}\right|<0.4$, the correlation between the two variables is weak. When $0<\left|R^{2}\right|<0.2$, the correlation between the two variables is extremely weak or uncorrelated.

\subsection{Gray Correlation Analysis}

Gray correlation analysis is a multi-factor statistical method that can analyze the degree of correlation among multiple factors [21,22]. The details are as follows: 
(1) The reference sequence $X_{0}(k)$ and the comparative sequence $X_{i}(k)$ are selected from the data obtained from various experiments, as shown in Equation (7).

$$
\begin{gathered}
X_{0}=X_{0}(1), X_{0}(2), \ldots, X_{0}(n) \\
X_{1}=X_{1}(1), X_{1}(2), \ldots, X_{1}(n) \\
\ldots \\
X_{m}=X_{m}(1), X_{m}(2), \ldots, X_{m}(n)
\end{gathered}
$$

where, $k=1,2,3, \ldots, n, i=1,2,3, \ldots, m$.

(2) To reduce the influence of the difference between the maximum and minimum values in the sequence, the sequence needs to be normalized, as shown in Equation (8).

$$
x_{i}(k)=\frac{X_{i}(k)}{\frac{1}{n} \sum_{i}=1^{n} X_{i}}(k)
$$

where, $i=0,1,2,3, \ldots, m$.

(3) The gray correlation coefficient is calculated by Equation (9).

$$
x_{i}(k)=\frac{\operatorname{minmin}_{i}\left|x_{0}(k)-x_{i}(k)\right|+\underset{i}{\operatorname{raxaxax}}\left|x_{0}(k)-x_{i}(k)\right|}{\left|x_{0}(k)-x_{i}(k)\right|+\underset{i}{\operatorname{raxmax}}\left|x_{0}(k)-x_{i}(k)\right|}
$$

where, $\left|x_{0}(k)-x_{i}(k)\right|=D_{i}(k)$ is called the absolute deviation between $x_{0}$ and $x_{i}$ at point $k$; $\operatorname{minmin}_{i}\left|x_{0}(k)-x_{i}(k)\right|$ is called the tow-grade minimum difference; $\max _{i} \max _{k}\left|x_{0}(k)-x_{i}(k)\right|$ is called the tow-grade maximum difference; and $\rho$ is the distinguishing coefficient, generally $\rho=0.5$.

(4) The relational degree is calculated by Equation (10).

$$
r_{i}=\frac{1}{n} \sum_{k=1}^{n} x_{i}(k)
$$

(5) According to the principle of the gray correlation degree analysis, the comparative sequence with a high relational degree is the closest to the reference sequence, which is the most important factor that affects the reference sequence.

\section{Results and Discussion}

\subsection{Characterizations of IPEs}

\subsubsection{FTIR Analyses}

A strong peak is observed at $3000 \mathrm{~cm}^{-1}$ to $2750 \mathrm{~cm}^{-1}$, mainly corresponding to the stretching vibration of the $\mathrm{C}-\mathrm{H}$ bond in IPEs (Figure 3). Peaks are observed at $1500 \mathrm{~cm}^{-1}$ to $1000 \mathrm{~cm}^{-1}$, characteristic of stretching vibrations of $\mathrm{C}-\mathrm{C}$ and $\mathrm{C}-\mathrm{O}$ bonds. Weak peaks corresponding to the stretching vibrations of $\mathrm{N}-\mathrm{H}$ and $\mathrm{C}=\mathrm{C}$ bonds are observed at $3500 \mathrm{~cm}^{-1}$ to $3250 \mathrm{~cm}^{-1}$ and $2250 \mathrm{~cm}^{-1}$ to $1500 \mathrm{~cm}^{-1}$, respectively. In addition, IPEs mainly comprise hydrophobic hydrocarbon groups, which are predominantly produced by the straight-chain hydrocarbon structure in paraffins. Meanwhile, IPEs contain a small amount of the hydrophilic amide group (-CONH-), indicating that IPEs with an excellent emulsion property can be stably distributed in the water phase. Moreover, similar peak locations are observed for anionic paraffin emulsion (APE), cationic paraffin emulsion (CPE), and non-ionic paraffin emulsion (NPE). However, the peak intensities of APE, CPE, and NPE are slightly different due to different ionic emulsifiers. 


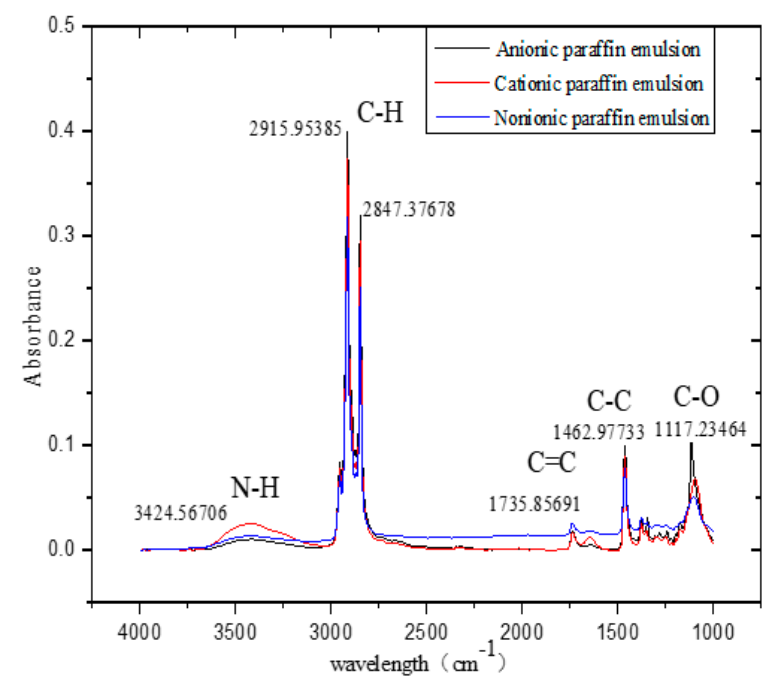

Figure 3. Fourier transform infrared (FTIR) spectroscopy of IPEs.

\subsubsection{Microstructural Analyses}

The particle size of IPEs was observed by TRPM (Figure 4). Paraffin particles are small and uniformly distributed, demonstrating an excellent emulsion property; this property is conducive to the mixing of cement-based materials with IPEs. Notably, NPE exhibits the lowest particle size, which is more conducive to the distribution of paraffin particles of NPE in cement-based materials.
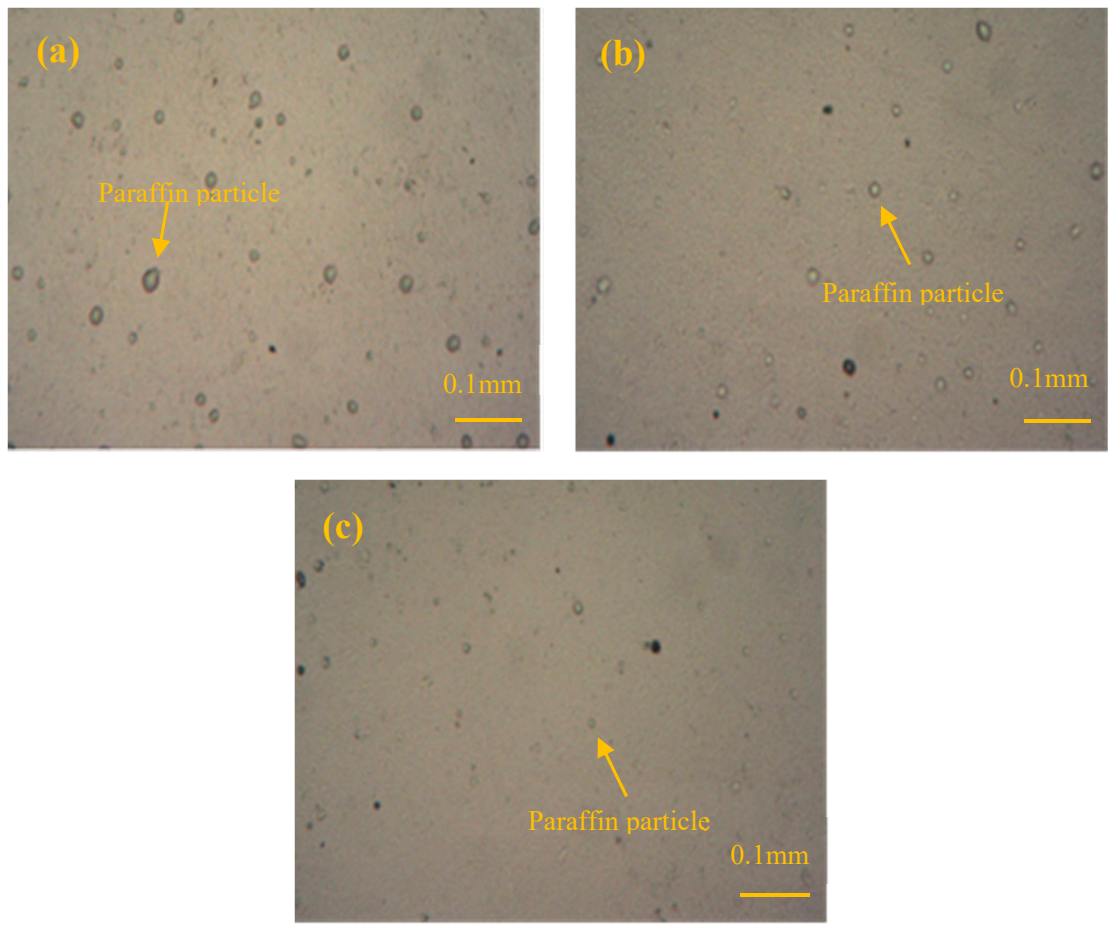

Figure 4. Transmission and reflection polarizing microscope (TRPM) photographs of IPEs $(\times 100)$ : (a) anionic paraffin emulsion (APE), (b) cationic paraffin emulsion (CPE) and (c) non-ionic paraffin emulsion (NPE). 


\subsection{Properties of Cement-Based Materials with IPEs}

\subsubsection{Compressive Strength}

Figure 5 shows the change in the compressive strength of cement paste specimens with different IPE doses at a curing age of 28 days. Generally, the compressive strength of cement paste specimens with IPEs is less than that of the control group. Based on the observation in Figure 5, the compressive strength of cement paste specimens increases with the increase in the IPE dose when the IPE dose is less than $4.0 \%$ (except the control group). Second, the compressive strength of cement paste specimens decreases with the increase in the IPE dose when the IPE dose is greater than $4.0 \%$. Figure 6 shows digital photographs of cement paste specimen sections with different doses of NPE. The number of pores decreases in the following order: Figure $6 d>$ Figure $6 b>$ Figure $6 c>$ Figure $6 a$. Meanwhile, the pore is filled by NPE in Figure 6c.

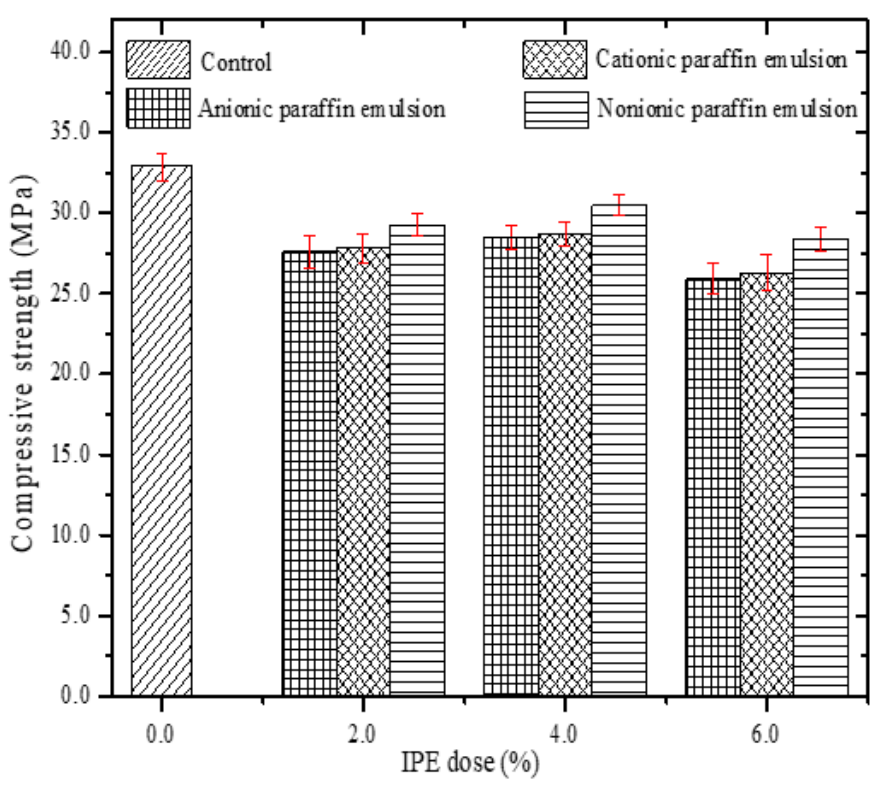

Figure 5. Compressive strength of cement paste with different IPE doses.

The change in the compressive strength and number of pores in cement-based materials is related to the following facts:

(1) Paraffin particles can affect cement hydration, leading to a higher number of internal pores in the cement paste specimens with IPEs than that in the control group. Therefore, the compactness of cement paste specimens with IPEs decreases, leading to a lower compressive strength of cement paste specimens with IPEs than that of the control group.

(2) Paraffin particles mainly play a role in filling the internal pores of cement paste specimens to reduce the porosity and improve the compressive strength at an IPE dose of less than $4.0 \%$ (except the control group). Thus, the compressive strength of cement paste specimens increases with the IPE dose.

(3) Excess paraffin particles adsorbed on the cement surface can affect cement hydration when the IPE dose is greater than $4.0 \%$. Moreover, the network connection among the cement hydrates is affected due to paraffin particles, which increases the porosity of cement paste specimens. Therefore, the compressive strength of cement paste specimens decreases with the increase in the IPE dose. 

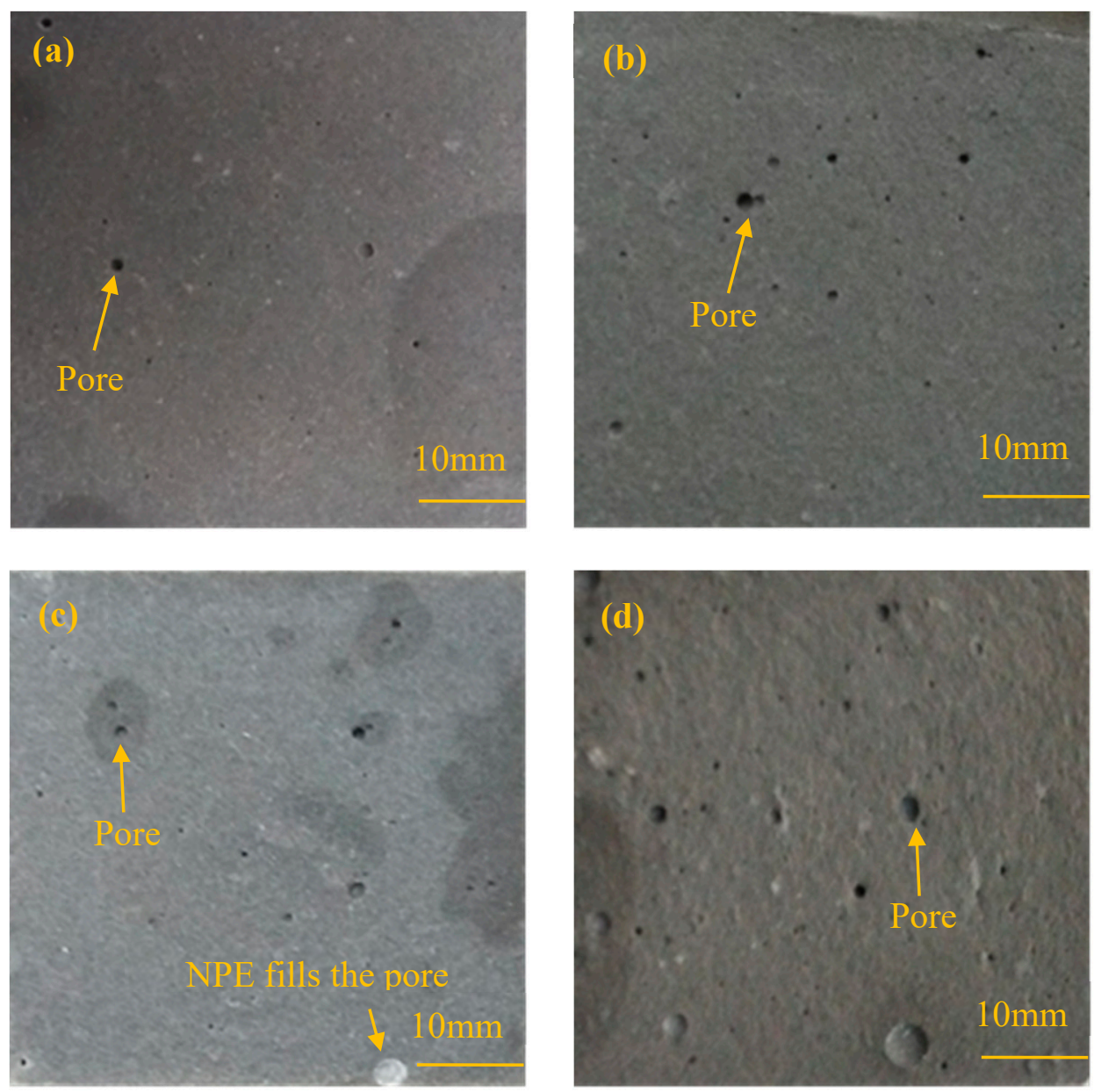

Figure 6. Digital photographs of cement paste with different NPE doses: (a) $0 \%$, (b) $2.0 \%$, (c) $4.0 \%$ and (d) $6.0 \%$.

\subsubsection{Impermeability Results}

Figure 7 shows the change in the impermeability pressure of cement mortar specimens with different IPE doses at a curing age of $28 \mathrm{~d}$. The impermeability pressure of cement mortar specimens with IPEs is higher than that of the control group, which is mainly related to the hydrophobicity of IPEs. Correspondingly, paraffin particles can fill internal pores of cement mortar specimens and enclose cement hydrates to impart hydrophobicity to the inside of cement mortar specimens; on the other hand, the IPE coating can prevent water penetration, and the newly exposed part of cement mortar specimens after damage is hydrophobic (Figure 8). In addition, the impermeability pressure clearly increases first and then decreases with the increase in the IPE dose. Hence, the IPE dose of the cement mortar is extremely high to retard the cement hydration, leading to the decrease in impermeability.

Combined with the compressive strength and impermeability tests, notably, cement mortar specimens and cement paste specimens with 4.0\% NPE exhibit the highest impermeability and highest compressive strength (except the control group), respectively, which is mainly related to the non-ionic property of NPE. Therefore, NPE is not easily adsorbed on the cement surface, leading to a lower adverse effect on cement hydration than APE and CPE. Besides, hydrophilic groups of NPE mainly comprise-CONH- (oxygen-containing functional groups), leading to the strong adsorption of NPE on water molecules. Thus, NPE is conducive to the hydration of the surrounding cement. Correspondingly, the compactness of specimens with NPE is much better than that of specimens with APE and CPE, leading to a higher compressive strength and impermeability for specimens with NPE than those for specimens with APE and CPE. 


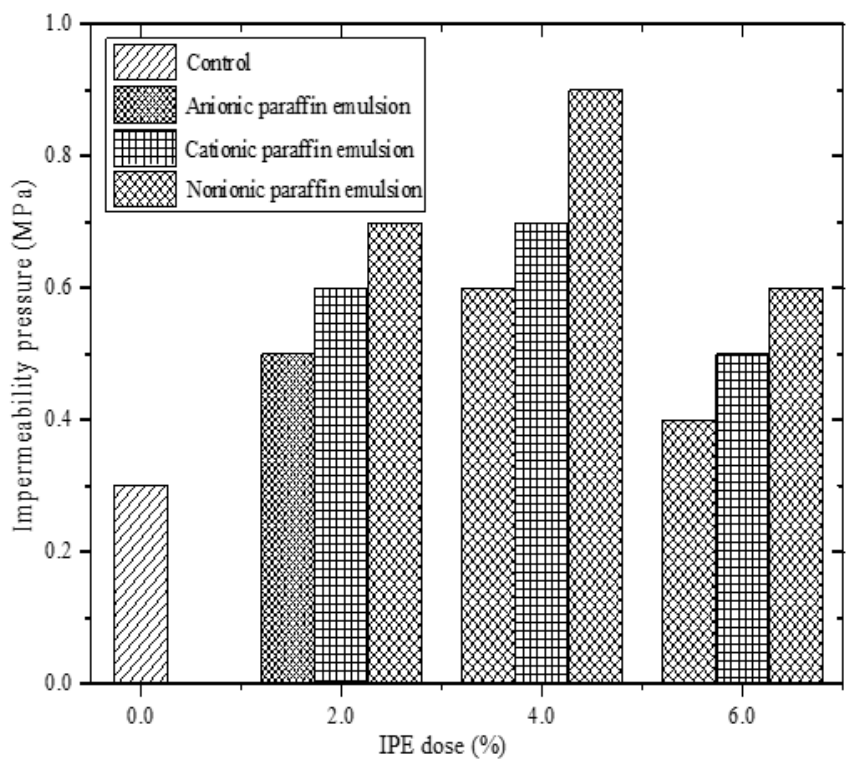

Figure 7. Impermeability pressure of cement mortar with different IPE doses.

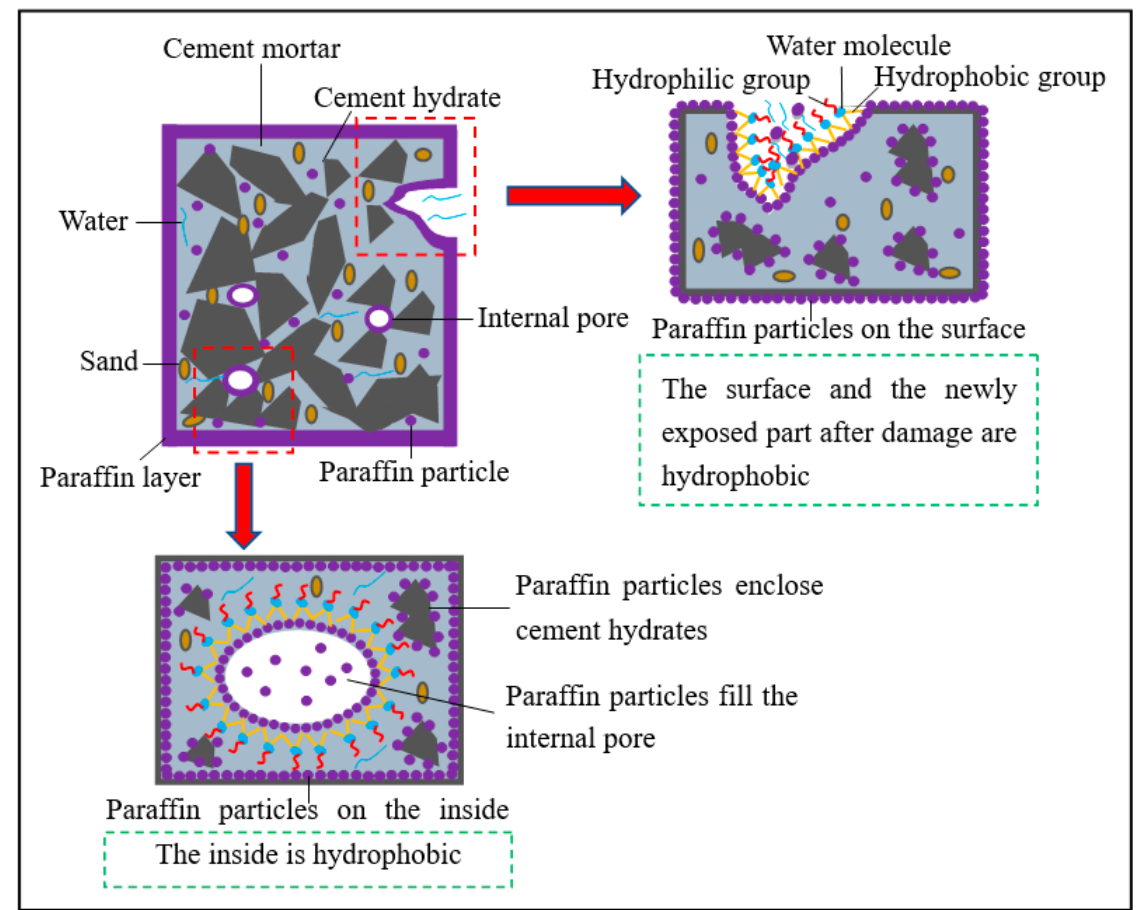

Figure 8. Diagram of internal and external hydrophobicity.

\subsubsection{Apparent Contact Angle}

According to the above test results, the apparent contact angle test for the cement powder with $4.0 \%$ IPEs was carried out (Figure 9). The apparent contact angle of the control group is $47.301^{\circ}$. The apparent contact angles of the cement powder with APE, CPE, and NPE are 88.765, $88.892^{\circ}$, and $88.926^{\circ}$, respectively. Notably, the average apparent contact angle of the cement powder with IPEs is increased by $88.86 \%$. Therefore, the cement powder with IPEs exhibits excellent hydrophobicity. In addition, the apparent contact angle of the cement powder with NPE is higher than that of the cement powder with APE and CPE. Thus, the hydrophobicity of the cement powder with NPE is higher than that of the cement powder with APE and CPE. 

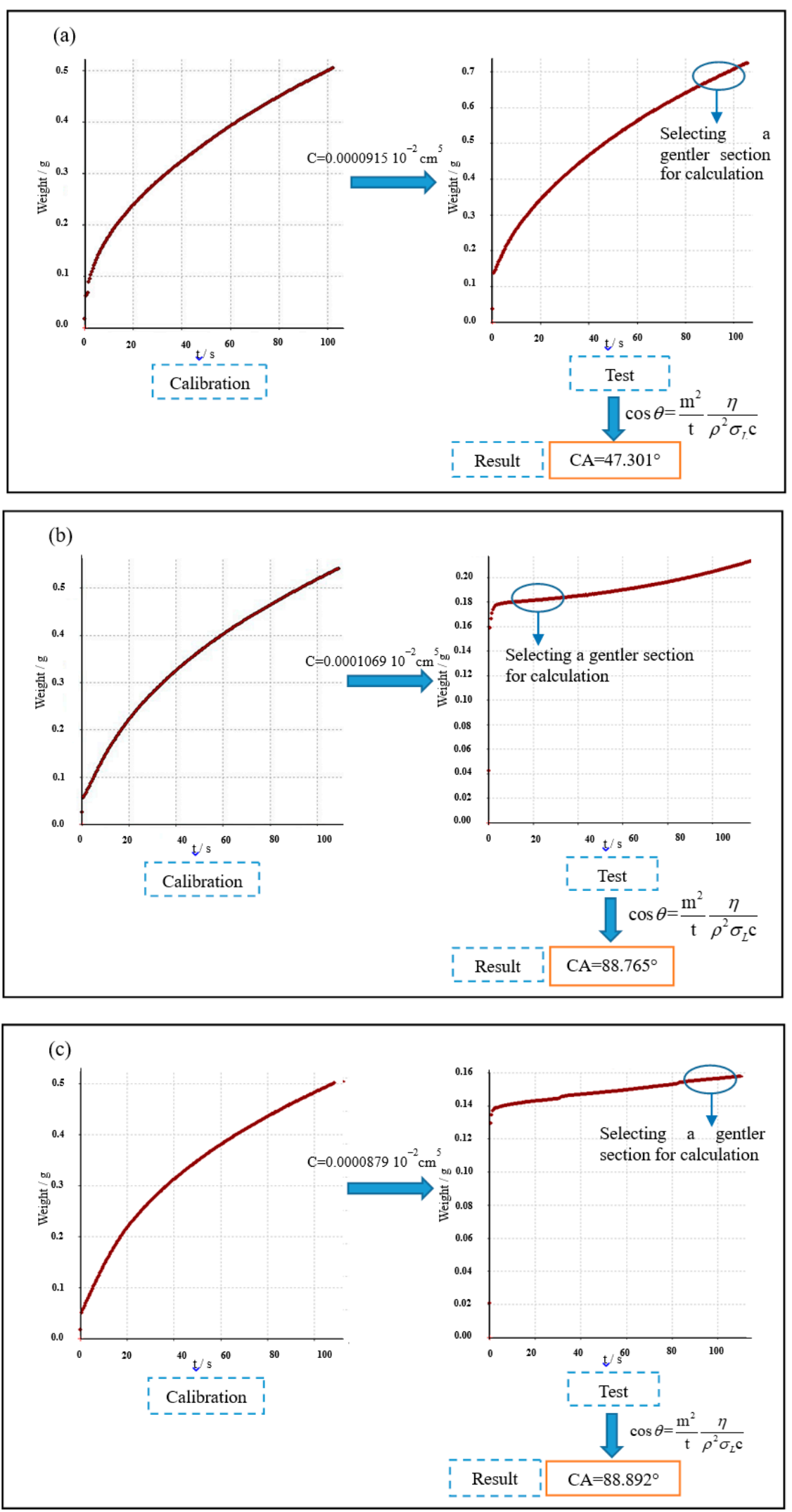

Figure 9. Cont. 


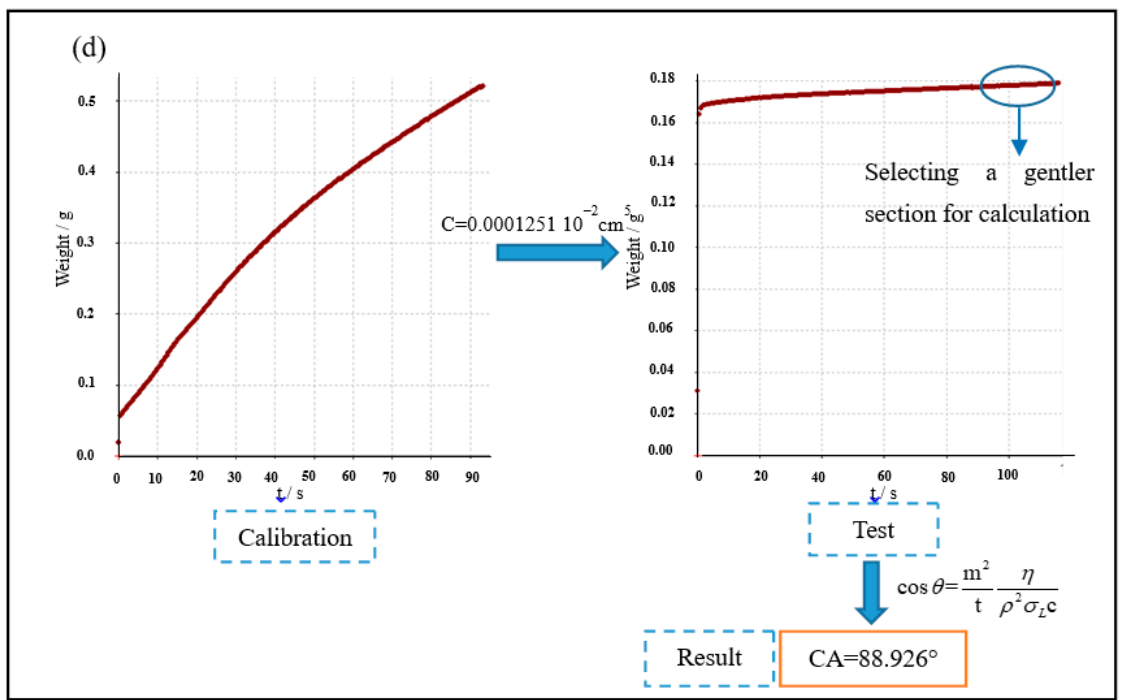

Figure 9. Apparent contact angle value of cement powder with 4.0\% IPEs: (a) cement powder, (b) cement powder with APE, (c) cement powder with CPE and (d) cement powder with NPE.

\subsubsection{Microstructures}

Figure 10 shows the scanning electron microscopy (SEM) photographs of the cement paste with $4.0 \%$ IPEs at a curing age of $28 \mathrm{~d}$. Cement hydrates are clearly observed in Figure 10. The amount of cement hydrates decreases in the following order: Figure 10a $>$ Figure 10d $>$ Figure 10b > Figure 10c. Furthermore, hydrates of the cement paste with NPE are similar to those of the control group.
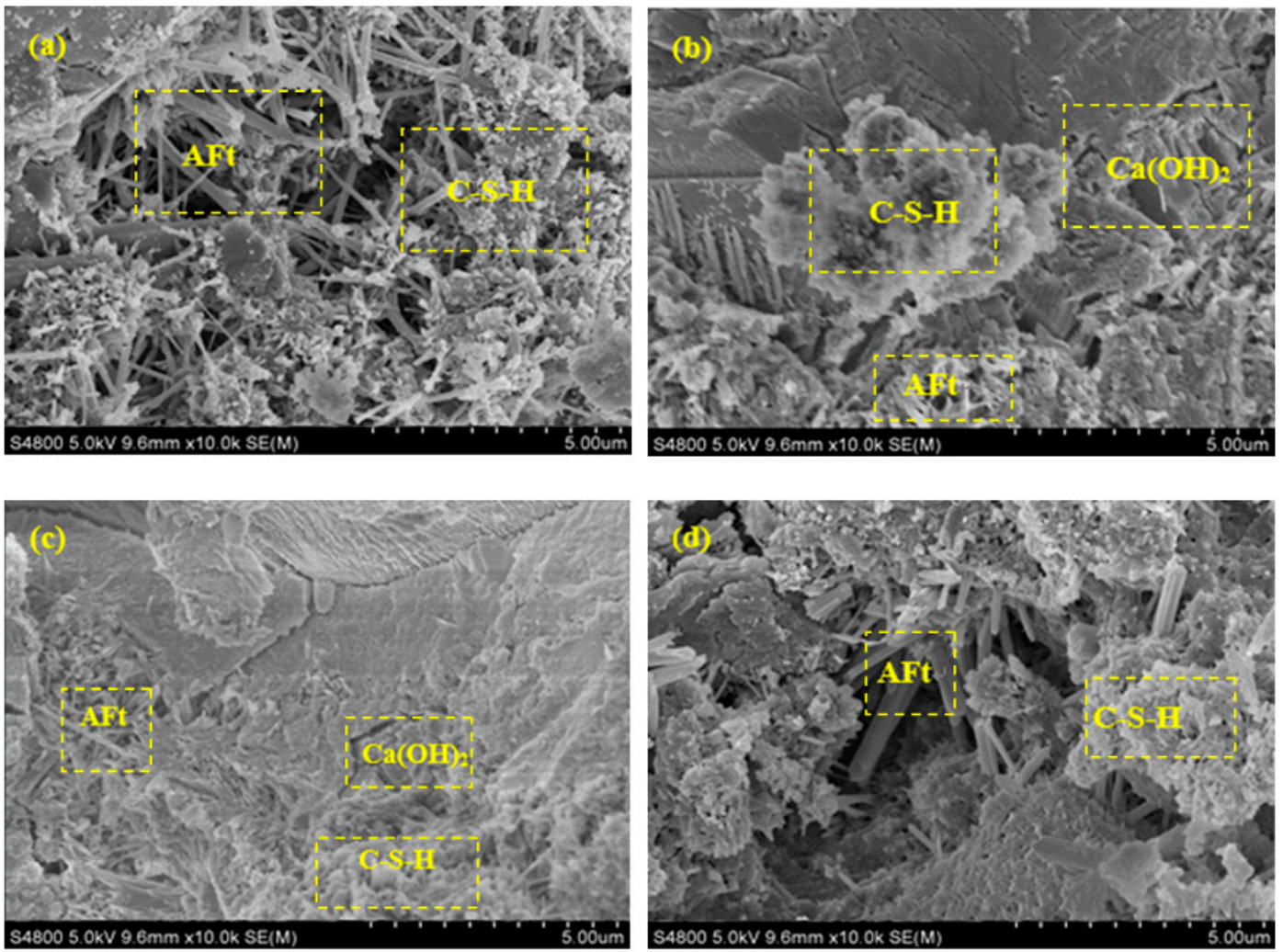

Figure 10. Scanning electron microscopy (SEM) photographs of cement paste with $4.0 \%$ IPEs at 28 days curing ages: (a) cement paste, (b) cement paste with APE, (c) cement paste with CPE and (d) cement paste with NPE. 
The change in the cement hydrates of cement-based materials is related to the following facts:

(1) According to the Cassie-Baxter model [23,24], water does not easily wet the cement surface due to the hydrophobicity of IPEs, leading to the interception of gas on the cement surface to produce a gas film and hindering the complete hydration of cement. Thus, the amount of hydrates of the cement paste with IPEs is less than that of the control group, leading to lower compressive strength and compactness for the cement paste with IPEs than those for the control group.

(2) Paraffin particles in APE and CPE can be adsorbed on cement particles or hydrates more easily than those in NPE, which hinders the hydration of cement and decreases the compactness of cement hydrates. Therefore, the content of flaky calcium hydroxide in the cement paste with APE and CPE is greater than that in the cement paste with NPE; the contents of aciculate ettringite crystal and hydrated calcium silicate gel in the cement paste with APE and CPE are less than those in the cement paste with NPE, leading to lower compressive strength, impermeability, and apparent contact angle for the cement paste with APE and CPE than those for the cement paste with NPE.

\subsubsection{Correlation Analyses}

In this work, the impermeability pressure of cement-based materials with $4 \%$ IPEs was selected as the reference sequence $\left(X_{0}\right)$, the compressive strength of cement-based materials with $4 \%$ IPEs was selected as a comparative sequence $\left(\mathrm{X}_{1}\right)$, and the apparent contact angle of cement-based materials with $4 \%$ IPEs was selected as a comparative sequence $\left(X_{2}\right)$. Table 6, Figures 11 and 12 show the results of the gray correlation analysis, non-linear correlation analysis, and linear correlation analysis, respectively.

Table 6. Results of correlation.

\begin{tabular}{ccc}
\hline Correlation & Properties & Impermeability Pressure \\
\hline Gray correlation & Apparent contact angle & 0.77376 \\
Non-linear correlation & Compressive strength & 0.55648 \\
Linear correlation & Apparent contact angle & 0.82002 \\
\hline
\end{tabular}

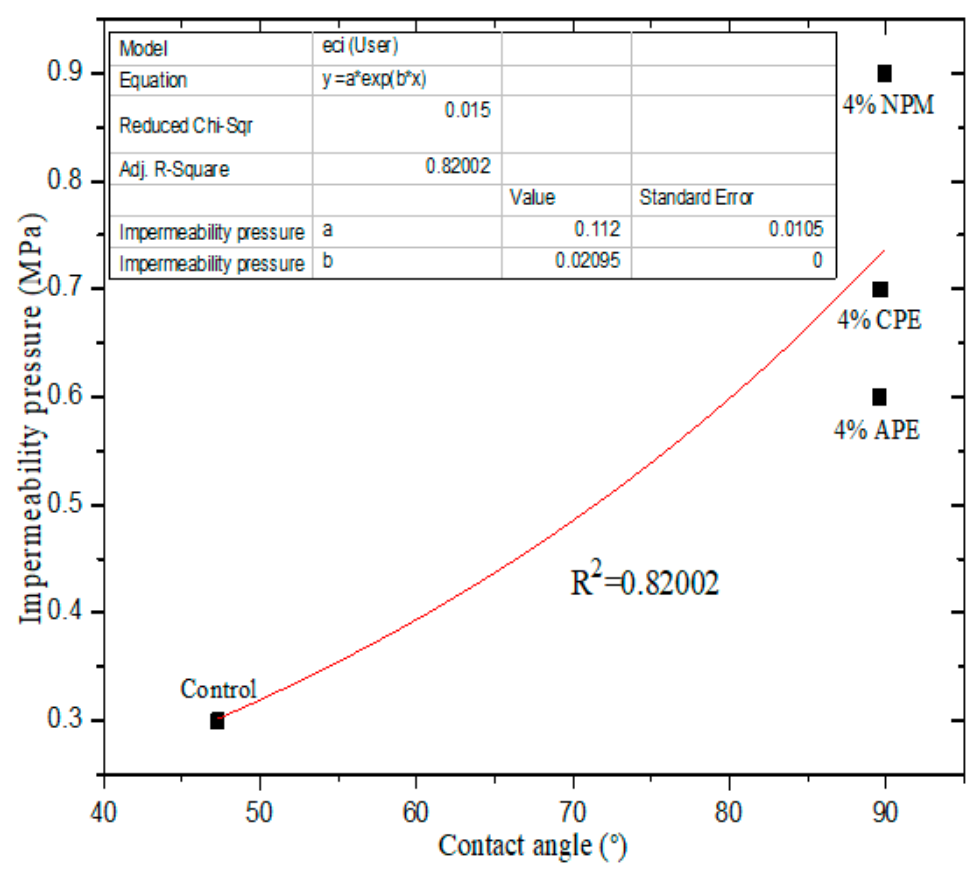

Figure 11. Correlation between apparent contact angle and impermeability pressure. 


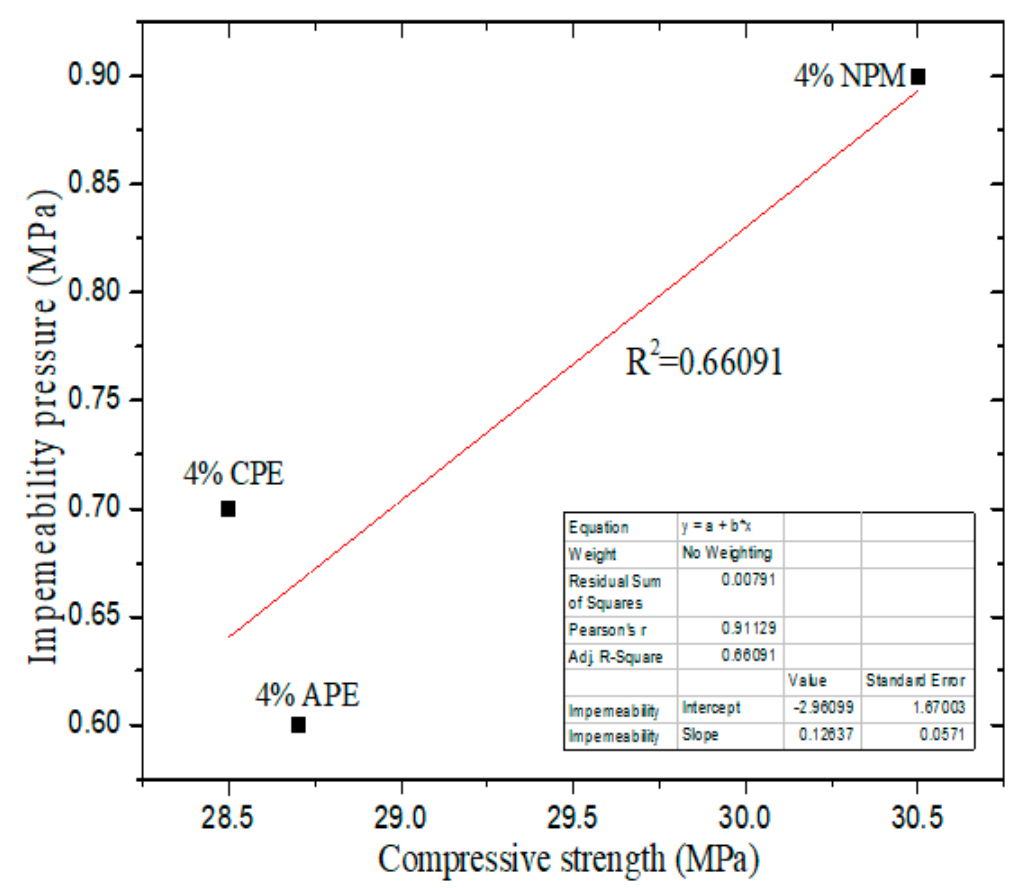

Figure 12. Correlation between compressive strength and impermeability pressure with IPEs.

Table 6 shows that $r_{1}$ (0.77376) is greater than $r_{2}$ (0.55648), which indicates that the apparent contact angle is the main factor that affects the impermeability. The apparent contact angle is positively correlated with the impermeability pressure. The higher the apparent contact angle, the higher the impermeability pressure, that is, the stronger the hydrophobicity of cement-based materials (Figure 11). In addition, the compressive strength is positively correlated with the impermeability pressure of cement-based materials with IPEs (Figure 12). However, from Figures 5 and 7, the compressive strength for the control group is high, but its impermeability is not necessarily high. Therefore, the control group is not shown in Figure 12. Meanwhile, attention should be focused on the compressive strength when considering the impact of impermeability and apparent contact angle on the hydrophobicity of cement-based materials.

\section{Conclusions and Recommendations}

In this work, the effect of cement-based materials incorporated with IPEs on the hydrophobicity was examined by macroscopic and microscopic tests as well as correlation analyses. The effect of IPEs on the hydrophobicity improvement of cement-based materials was analyzed. In addition, the optimal type and the recommended dose of IPEs were suggested. The following conclusions and recommendations can be drawn:

(1) The impermeability of cement mortar specimens with IPEs reflects exceptional hydrophobicity. Notably, cement mortar with $4.0 \%$ NPE exhibits outstanding hydrophobicity.

(2) The apparent contact angle of cement powder with IPEs is significantly higher than that of the control group, indicating that IPEs exhibit excellent hydrophobicity. Notably, the apparent contact angle of cement powder with NPE is near $90^{\circ}$.

(3) The microstructures of cement paste with NPE are clearer than those of the cement paste with APE and CPE. Meanwhile, the microstructures of cement paste with NPE are similar to that of the control group.

(4) The apparent contact angle is the main factor that affects the impermeability. Notably, attention should be focused on the compressive strength when considering the effect of impermeability and apparent contact angle on the hydrophobicity. 
(5) The compressive strength of cement-based materials with $4.0 \%$ NPE is considerably similar to that of the control group. However, NPE adversely affects the compressive strength. Therefore, we recommend that NPE can be mixed with mineral admixtures to improve the compressive strength of cement-based materials.

\section{Further Research}

Water can influence the cement hydration and concrete durability with different curing ages. Suitable water absorption can be beneficial for consolidating the concrete with positive effects in its resistance properties. However, excessive or short water absorption can result in the protection deterioration of concrete. Therefore, it is necessary to study the influence of the introduction of NPE on concrete durability in further research.

Author Contributions: Conceptualization, J.H. and Z.W.; methodology, H.G.; software, Y.W.; validation, J.H., Z.W. and H.G.; formal analysis, J.H.; investigation, J.H.; data curation, J.H.; writing—original draft preparation, J.H.; writing-review and editing, Z.W.; project administration, Z.W.; funding acquisition, Z.W. All authors have read and agreed to the published version of the manuscript.

Funding: This work is supported from Opening Foundation of Research and Development Center of Transport Industry of Technologies, Materials and Equipment of Highway Construction and Maintenance. (Gansu Road and Bridge Construction Group) (No. GLKF201806), Key Research and Development Program of Shaanxi Province of China (No. 2019GY-174), Science and Technology Development Project of Xinjiang Production and Construction Corps (No. 2019AB013), Henan Transportation Science and Technology Project (No. 2019J1) and the Fundamental Research Funds for the Central Universities of China (No. 300102310501). The authors also thank to the reviewers for their valuable comments and suggestions concerning our manuscript.

Conflicts of Interest: The authors declare no conflict of interest.

\section{References}

1. Zheng, K.; Yang, X.; Chen, R.; Xu, L. Application of a capillary crystalline material to enhance cement grout for sealing tunnel leakage. Constr. Build. Mater. 2019, 214, 497-505. [CrossRef]

2. Azarsa, P.; Gupta, R.; Biparva, A. Inventive Microstructural and Durability Investigation of Cementitious Composites Involving Crystalline Waterproofing Admixtures and Portland Limestone Cement. Materials 2020, 13, 1425. [CrossRef]

3. Min, H.; Song, Z. Investigation on the Sulfuric Acid Corrosion Mechanism for Concrete in Soaking Environment. Adv. Mater. Sci. Eng. 2018, 2018, 1-10. [CrossRef]

4. Wang, Z.; Wu, J.; Zhao, P.; Dai, N.; Zhai, Z.; Ai, T. Improving cracking resistance of cement mortar by thermo-sensitive poly N-isopropyl acrylamide (PNIPAM) gels. J. Clean. Prod. 2018, 176, 1292-1303. [CrossRef]

5. $\mathrm{Hu}, \mathrm{X} . ; \mathrm{He}, \mathrm{C} . ;$ Feng, K.; Liu, S.; Walton, G. Effects of polypyrrole coated rebar on corrosion behavior of tunnel lining with the combination effect of sustained loading and pre-existing cracks when exposed to chlorides. Constr. Build. Mater. 2019, 221, 318-331. [CrossRef]

6. He, R.; Dai, N.; Wang, Z. Thermal and Mechanical Properties of Geopolymers Exposed to High Temperature: A Literature Review. Adv. Civ. Eng. 2020, 2020, 1-17. [CrossRef]

7. Bušić, R.; Benšić, M.; Miličević, I.; Strukar, K. Prediction Models for the Mechanical Properties of Self-Compacting Concrete with Recycled Rubber and Silica Fume. Materials 2020, 13, 1821. [CrossRef] [PubMed]

8. Liu, P.; Gao, Y.; Wang, F.; Yang, J.; Yu, X.; Zhang, W.; Yang, L. Superhydrophobic and self-cleaning behavior of Portland cement with lotus-leaf-like microstructure. J. Clean. Prod. 2017, 156, 775-785. [CrossRef]

9. Wang, F.; Pi, J.; Song, F.; Feng, R.; Xu, C.; Wang, X.-L.; Wang, Y. A superhydrophobic coating to create multi-functional materials with mechanical/chemical/physical robustness. Chem. Eng. J. 2020, 381, 122539. [CrossRef]

10. He, R.; Zheng, S.; Gan, V.J.; Wang, Z.; Fang, J.; Shao, Y. Damage mechanism and interfacial transition zone characteristics of concrete under sulfate erosion and Dry-Wet cycles. Constr. Build. Mater. 2020, 255, 119340. [CrossRef] 
11. Wang, Z.; Wang, P.; Guo, H.; Wang, X.; Li, G. Adhesion Improvement between RAP and Emulsified Asphalt by Modifying the Surface Characteristics of RAP. Adv. Mater. Sci. Eng. 2020, 2020, 1-10. [CrossRef]

12. Izarra, I.; Cubillo, J.; Serrano, A.; Rodríguez, J.; Carmona, M. A hydrophobic release agent containing $\mathrm{SiO} 2-\mathrm{CH} 3$ submicron-sized particles for waterproofing mortar structures. Constr. Build. Mater. 2019, 199, 30-39. [CrossRef]

13. Li, G.; Liu, S.; Niu, M.; Liu, Q.; Yang, X.; Deng, M. Effect of granulated blast furnace slag on the self-healing capability of mortar incorporating crystalline admixture. Constr. Build. Mater. 2020, 239, 117818. [CrossRef]

14. Hua, W.; Kar, P.; Roy, P.; Bu, L.; Shoute, L.C.T.; Kumar, P.; Shankar, K. Resistance of Superhydrophobic Surface-Functionalized TiO2 Nanotubes to Corrosion and Intense Cavitation. Nanomaterials 2018, 8, 783. [CrossRef]

15. Liu, J.; Janjua, Z.A.; Roe, M.; Xu, F.; Turnbull, B.; Choi, K.-S.; Hou, X. Super-Hydrophobic/Icephobic Coatings Based on Silica Nanoparticles Modified by Self-Assembled Monolayers. Nanomaterials 2016, 6, 232. [CrossRef]

16. Vogel, F.; Sovják, R.; Pešková, Š. Static response of double shell concrete lining with a spray-applied waterproofing membrane. Tunn. Undergr. Space Technol. 2017, 68, 106-112. [CrossRef]

17. Li, R.; Hou, P.; Xie, N.; Ye, Z.; Cheng, X.; Shah, S.P. Design of SiO2/PMHS hybrid nanocomposite for surface treatment of cement-based materials. Cem. Concr. Compos. 2018, 87, 89-97.

18. Feng, Z.; Wang, F.; Xie, T.; Ou, J.; Xue, M.; Li, W. Integral hydrophobic concrete without using silane. Constr. Build. Mater. 2019, 227, 116678. [CrossRef]

19. Zhu, Y.-G.; Kou, S.-C.; Poon, C.-S.; Dai, J.-G.; Li, Q.-Y. Influence of silane-based water repellent on the durability properties of recycled aggregate concrete. Cem. Concr. Compos. 2013, 35, 32-38. [CrossRef]

20. Ministry of Housing and Urban-Rural Development of the People's Republic of China. Standard for Test Method of Basic Properties of Construction Mortar, JGJ/T 70-2009; China Architecture \& Building Press: Beijing, China, 2009.

21. Wang, Z.; Dai, N.; Wang, X.; Zhang, J.; Guo, H. Laboratory investigation on effects of microwave heating on early strength of cement bitumen emulsion mixture. Constr. Build. Mater. 2020, 236, 117439. [CrossRef]

22. Zhenjun, W.; Nan, D.; Xiaofeng, W.; Gang, L.; Haoyan, G. Early-stage road property improvements of cold recycled asphalt emulsion mixture with microwave technology. J. Clean. Prod. 2020, 263, 121451. [CrossRef]

23. Deng, Y.; Mager, D.; Bai, Y.; Zhou, T.; Liu, Z.; Wen, L.; Wu, Y.; Korvink, J.G. Inversely designed micro-textures for robust Cassie-Baxter mode of super-hydrophobicity. Comput. Methods Appl. Mech. Eng. 2018, 341, 113-132. [CrossRef]

24. Liu, T.; Chen, Z.; Kim, C.-J. A dynamic Cassie-Baxter model. Soft Matter 2015, 11, 1589-1596. [CrossRef] [PubMed]

(C) 2020 by the authors. Licensee MDPI, Basel, Switzerland. This article is an open access article distributed under the terms and conditions of the Creative Commons Attribution (CC BY) license (http://creativecommons.org/licenses/by/4.0/). 